\title{
Reconstructing crown shape from stem diameter and tree position to supply light models. I. Algorithms and comparison of light simulations
}

\author{
Alexandre Piboule*, Catherine Collet, Henri Frochot, Jean-François DhÔTE \\ Laboratoire d'Étude des Ressources Forêt-Bois, UMR INRA-ENGREF 1092, Institut National de la Recherche Agronomique, \\ 54280 Champenoux, France
}

(Received 11 January 2004; accepted 29 June 2005)

\begin{abstract}
Light models provide an interesting way to analyse the influence of the forest canopy on understory biological processes but need a detailed description of tree crowns, requiring many field measurements. This study proposes supplying light models with only stem diameter and tree position and reconstructing crowns using diameter-related allometric relations. First, the diameter-related relations for total height, crown base height and mean crown radius were established for each species. Second, two reconstruction methods were compared: a simple isotropic method and a more sophisticated method, the Crown Reconstruction by Overlap Minimisation method. The latter method gave better results than the simpler one, even if some small bias was not completely resolved in the darkest areas. However, using crown centre position instead of stem position resolved this bias.
\end{abstract}

crown reconstruction / crown competition / light model / heterogeneous forest / broadleaves

Résumé - Reconstruction de la forme des houppiers à partir du diamètre des arbres et de leur position pour alimenter un modèle de lumière. I. Algorithmes et comparaison des simulations de l'éclairement. Les modèles de lumière constituent un bon moyen pour analyser l'influence du couvert forestier sur les processus biologiques sous-couvert. Malheureusement ils nécessitent une description détaillée des houppiers des arbres, ce qui implique des mesures de terrain assez lourdes. Cet article propose d'alimenter les modèles de lumière uniquement avec le diamètre et la position des arbres, et de reconstituer les houppiers en utilisant des relations allométriques en fonction du diamètre à $1,30 \mathrm{~m}$. Les relations allométriques sont tout d'abord établies pour la hauteur totale, la hauteur de base de houppier et le rayon moyen du houppier, pour chaque espèce. Ensuite deux méthodes de reconstruction des houppiers sont comparées : une méthode simple dite isotrope et une plus sophistiquée, la méthode de reconstruction des houppiers par minimisation des chevauchements. Cette dernière donne de meilleurs résultats, même si un léger biais subsiste dans les zones les plus sombres. Cependant le fait d'utiliser la position des centres de houppiers au lieu de celle des troncs permet de complètement supprimer ce biais.

reconstruction des houppiers / compétition des houppiers / modèles de lumière / forêt hétérogène / feuillus

\section{INTRODUCTION}

Light availability under forest canopies is a key factor for understanding biological and ecological processes such as forest regeneration [46, 54], vegetation dynamics [15, 55, 65], soil biological activity [61] and many others [28, 35, 38]. In order to characterise light regimes and make comparisons between different stands and climatic conditions, many studies use Relative Light Intensity (RLI), which is also known as the Percentage of Above Canopy Light (PACL), in a forest context. Percentage of above canopy light is calculated over the considered period (often the whole vegetation period, when leaves have expanded) as the quantity of light at the considered point under the canopy, divided by the quantity of light above the canopy, where all sky directions are unobstructed.

A number of studies use direct measurement of PACL to analyse its influence on biological processes. However, since
PACL is directly determined by canopy structure, it would be possible to link PACL values under the canopy to stand-scale evaluated characteristics $[17,18,33,51,53,58]$. This approach is relatively effective but the relationships are generally obtained for a specific stand structure and silvicultural and ecological context. Heterogeneous canopies are often not well described using mean stand characteristics. Thus, this approach is not really intended for predicting spatial light regime variations, which can be very large under heterogeneous canopies. In the case of clearly-defined gaps, some solutions have been proposed $[7,8,20,53]$, but these methods are difficult to extend, as is, to more complex structures.

An approach used by several authors is to predict PACL from stand characteristics by explicitly modelling light transmission through a virtual representation of the canopy. Canopies may be represented using 3D architectural models describing trees at leaf level $[12,13,21]$. These models are very

\footnotetext{
* Corresponding author: alexandre.piboule@onf.fr
} 
precise but need a very detailed description of the canopy and are difficult to apply in forest stands. A second option is to represent the canopy using turbid medium models. These models define "simple" 3D volumes, where plant elements are supposed to be evenly distributed. Different models differ according to the volumes considered.

The canopy may be represented at the stand level by using one or more layers representing the entire canopy [3, 23, 34, $36,43,63]$. These models are well adapted to homogeneous stands but are not very effective in heterogeneously-structured canopies. Instead of layers, some models consider 3D-cells [16, $22,37,40,44,45]$, intended for more complex canopy structures. However, it is relatively difficult to characterise canopy cells in the field, particularly in forest contexts.

Another approach is to define canopy volumes at the individual tree level. These models represent the tree crown as a geometrical shape of various complexity: cylinder [2, 8, 9, 59], cone [1, 59], ellipsoid [1, 64], paraboloid [19, 59] or more complex solids $[5,10,31,39,59,60]$. Some other crown representations were proposed but not implemented in light models [14, 57]. This tree-level representation makes it possible to take differences among trees in horizontal and vertical crown shapes into account. Some models can represent asymmetricallyshaped crowns (asymmetric horizontally [5], vertically or both $[10,31])$, that closely fit the actual crown shapes. A few models can use sub-crown representations [50,64].

Tree-level models usually give an accurate prediction of PACL under or within the canopy, even in heterogeneous stands. The main drawback of these models is the large number of parameters that need to be provided for each tree modelled (tree total height, crown base height and crown radii, for example). In some studies, these parameters are measured on each tree of the simulated stand, requiring long and tedious measurements.

In this study, we tested the possibility of connecting a detailed light model to a crown reconstruction model and to using the crown model to supply the required individual crown data to the light model. This approach would make it possible to greatly reduce the number of measurements required, in order to simulate PACL distribution in existing stands. It would also make it possible to connect light models to spatially explicit stand growth models that do not simulate tree crown development, in order to simulate PACL in a stand at the same time as its growth.

The specific objective of this study was to establish and test methods to reconstruct individual tree crowns from simple measurements such as stem diameter and tree position, using diameter-related allometric relations for crown characteristics, in order to supply light models. Two main methods were considered: (1) a simple horizontally-isotropic crown reconstruction; and (2) an original asymmetrical crown creation method based on a Crown Reconstruction by Overlap Minimisation (CROM) algorithm. A spatially explicit light transmission model (tRAYci from Brunner [5]) was used to predict PACL in a stand where tree crowns were reconstructed, and the predicted PACL values were compared with light measurements taken in the real stand. Thus, our main objective was to obtain accurate and unbiased light prediction based on a smaller set of data. The geometric accuracy of individual crown reconstruction will be evaluated in a companion paper.

\section{MATERIALS AND METHODS}

\subsection{Study site and stand description}

The study site is located on a limestone plateau in Lorraine, France ( $\left.49^{\circ} 04^{\prime} 40^{\prime \prime} \mathrm{N}, 6^{\circ} 01^{\prime} 02^{\prime \prime} \mathrm{E}\right)$, at approximately $300 \mathrm{~m}$ above sea level. Soil characteristics are homogeneous over the whole study site. The stand is a former coppice-with-standards broadleaved stand. After the last coppice cut in the 1960's, the stand was being converted into a mixed-species even-aged forest. A storm in 1989 created many gaps of various sizes. The canopy is very closed except in the gaps because very few thinning operations have been carried out since the 1960's. Standards are mainly beech (Fagus sylvatica L.), sycamore (Acer pseudoplatanus L.), Norway maple (Acer platanoides L.) and oak (Quercus petraea (Mattus.) Liebl. and Quercus robur L.), with some scattered wild service trees (Sorbus torminalis (L.) Crantz). Coppice is mainly composed of hornbeams (Carpinus betulus L.) and some field maples (Acer campestre L.), limes (Tilia cordata Mill. and Tilia platyphyllos Scop.) and white beams (Sorbus aria (L.) Crantz) (Fig. 1). The basal area is approximately $30 \mathrm{~m}^{2} \cdot \mathrm{ha}^{-1}$.

The study site contained two separate plots (Plots 1 and 2, Fig. 2a). In each plot, a study area was delimited, with gaps of different sizes. Plot 1 contains several small gaps ranging from 0.01 to 0.20 ha. Plot 2 contains a single large gap of about 0.50 ha. The study areas of Plots 1 and 2 have a surface area of 1.11 and 0.15 ha, respectively. Two successive 20-m-wide buffer areas were created around each study area. The first buffer area brings the surface area of Plots 1 and 2 to 2.22 and 0.67 ha, respectively, and the second buffer area brings the surface area of Plots 1 and 2 to 3.58 and 1.44 ha, respectively.

\subsection{Light measurements}

Two kinds of light measurements were made:

- Light estimation from hemispherical photographs to calibrate the tRAYci light model.

- Light sensor measurements to evaluate the light simulations obtained with the tRAYci model.

\subsubsection{Light sensors}

We used amorphous silicon sensors (CBE sensors from Solems S.A., Palaiseau, France) [11]. On May 18-19, 2004, CBE sensors were calibrated against a quantum PAR sensor (LI-191SB from Li-Cor Inc., Lincoln, NE, USA). A fourth order polynomial without intercept term was adjusted in order to predict PPFD from output voltage of the sensors.

Thirty-seven sensors were used on three transects. Two 36-m-long transects with 10 sensors each (Transects 1 and 2) were created across two small gaps (less than 0.05 ha) in Plot 1. A 60-m-long transect (17 sensors, Transect 3 ) was created perpendicular to the edge of the large gap (more than $0.5 \mathrm{ha}$ ) in Plot 2. The sensors were installed at an interval of $4 \mathrm{~m}$ along the transects, and at a height of $1.5 \mathrm{~m}$, except near the edge of the gap in the third transect where the light gradient was the strongest and where the interval between two successive sensors was reduced to $2 \mathrm{~m}$. Each sensor was localised.

A full-light reference was installed at a distance of less than $500 \mathrm{~m}$ from the three transects. It was composed of three CBE sensors and one BF2 direct/diffuse light sensor (Delta-T Devices Ltd, Cambridge, UK). All sensors (transects and reference) were connected to CR10 data loggers (Campbell Scientific Ltd, Leicestershire, UK). Instantaneous values were measured every minute, and 30 -min-average values were stored. The measurements were made continuously from June 25 


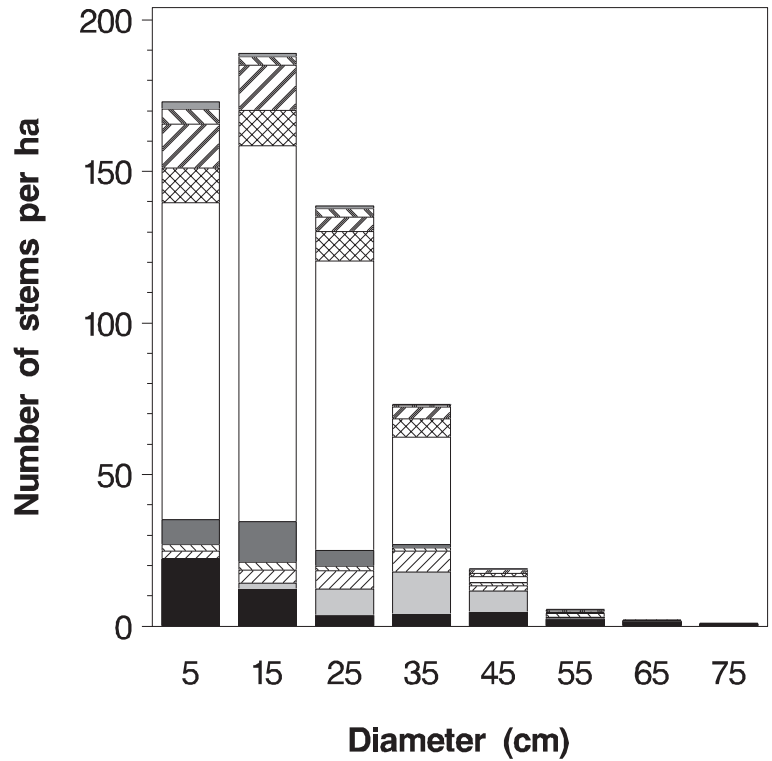

to August 2, 2004. Total PACL for this period was calculated for each sensor (sum of PPFD of the considered sensor/sum of the mean PPFD of the three reference sensors). The PDIF ratio was also calculated as \{diffuse PPFD / (diffuse + direct PPFD) $\}. P D I F$ over the whole period was $45.84 \%$. Out of the 39 days of measurements, 12 days were clear, nine days had some clouds, 11 days were cloudy and six days were completely overcast. The climate during the measurement period was representative of the local climate during the whole vegetation period.

\subsubsection{Hemispherical photographs}

A series of 137 hemispherical photographs was taken, sampling the whole study area of each plot. Colour photographs were taken with a digital camera (Coolpix 5000 with a FC-E8 fish-eye lens, Nikon Corporation, Tokyo, Japan), at a height ranging from 1.5 to $8 \mathrm{~m}$. A homemade auto-levelling mount and north indicator were used in combination with a remote control (Digisnaps 2500, Harbortronics, Gig Harbor, WA, USA). All photographs were taken after sunset, under clear sky conditions, thresholded with Adobe Photoshop 6 software and analysed with HemIMAGE [5] software. PACL was simulated for each sample point from June 25 to August 2, 2004. We used the measured PDIF value (45.84\%) and a Standard Overcast Sky Condition diffuse distribution (with a coefficient of $b=1.23$ ). The cosine correction option was used. For more details about the photography analysis, refer to [52].

\subsection{Light model}

TRAYci is a light interception model [5] designed to estimate PACL at any point in a forest stand, using a geometrical representation of the trees. The light spectrum range considered in tRAYci is the Photosynthetic Photon Flux Density (PPFD). As of this time, tRAYci has only been used in even-aged and irregular, pure and mixed conifers stands [5, 6, 30, 41, 42, 49], but is also intended for use in broadleaved stands. Only the tRAYci crown representation is described here. For more details about the model, see [5].

\subsubsection{Crown representation in $\mathrm{tRAYci}$}

Each tree stem is represented by a vertical cylinder. Its crown is represented by a geometrical volume (Fig. 3). The volume is centred
Others

Sorbus aria

Tillia sp.

Acer campestre

Carpinus betulus

Sorbus torminalis

Acer platanoides

Acer pseudoplatanus

Quercus sp.

Fagus sylvatica

Figure 1. Number of stems (per ha) for each class of diameter at $1.30 \mathrm{~m}$, by species. Number in X-axis represents class midpoints (for example, "5" means class "0-10 cm"). on a vertical axis $(A x)$ above the stem centre and is delimited at the top by total tree height (point $H$ ) and at the bottom by tree crown base height (point $B$ ). It is split into two parts: the upper crown section and the lower crown section, separated by the horizontal plane located at the height of maximum crown width (point $M$ ). In this plane, the crown extension is represented by four to eight radii from point $M$ (points $R_{i}$, $i$ from 1 to $4-8$ ). Each $R_{i}$ point is connected to both $H$ for upper crown section and $B$ for lower crown section, by curves defined by a shape parameter. A value of 2 for a shape parameter corresponds to the quarter ellipse formula [5, 39]. The shape parameters for upper and lower crown section are specified separately. In the horizontal plane, the crown radius between two successive radii $R_{k}$ and $R_{k+1}$ is extrapolated by the quarter ellipse formula. The foliage can be distributed evenly into the total crown volume or restricted to a crown shell at the periphery. Two crown shell thickness parameters are defined as a proportion of $B H$ length, separately for upper and lower crown sections. The Leaf Area Density parameter $\left(L A D\right.$, in $\left.\mathrm{m}^{2} \cdot \mathrm{m}^{-3}\right)$ defines the leaf area contained by the crown shell.

Total height, crown base height and the crown radii in four to eight directions are specified for each tree. Height of maximum crown width (expressed as the proportion $B M / B H$ ), the two shape parameters, the two shell thickness parameters and the $L A D$ parameter are specified at the species level.

\subsubsection{Field measurements}

In the study areas and in the first buffers, the following data were recorded for each tree with a diameter greater than $5 \mathrm{~cm}$ at a height of $1.30 \mathrm{~m}$ : species, diameter at $1.30 \mathrm{~m}$, stem centre position (distance and azimuth from reference grid points) and crown variables. Each crown was described as three heights (the total tree height, the crown base height defined as the base of the leaved-crown and the height of maximum crown width), the position of crown centre (from stem centre position) and eight crown radii. Height measurements were obtained with a Vertex III hypsometer (Haglöf Sweden AD., Långsele, Sweden). The crown centre was defined as the projection at ground level of the architectural centre of the crown at the height of maximum crown width. The stem centre was used as the crown centre whenever possible (i.e., when the two points were very close, less than $1 \mathrm{~m}$ ). The eight crown radii were determined for each tree from crown centre as follows: the crown projection was delimited by eight points visually 


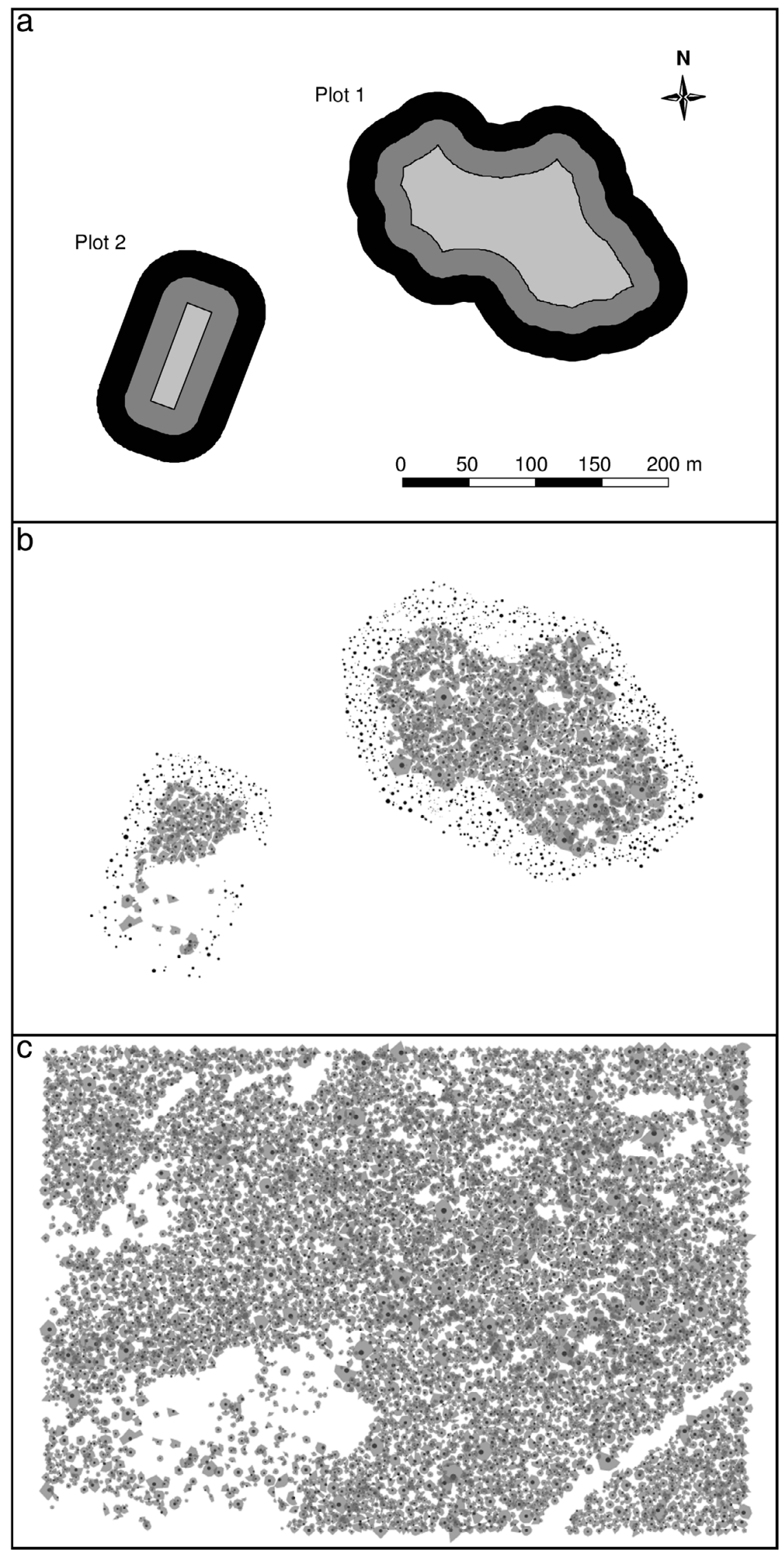

Figure 2. (a) The two plots, with the study area for each (in light grey), the first buffer (in dark grey) and the second buffer (in black). (b) The measured data on trees: stems are represented by solid black circles; the tree crowns are represented by grey polygons. (c) The simulation plot after stand generation in not-measured areas. The three figures represent the same stand area and are drawn using the same scale. 


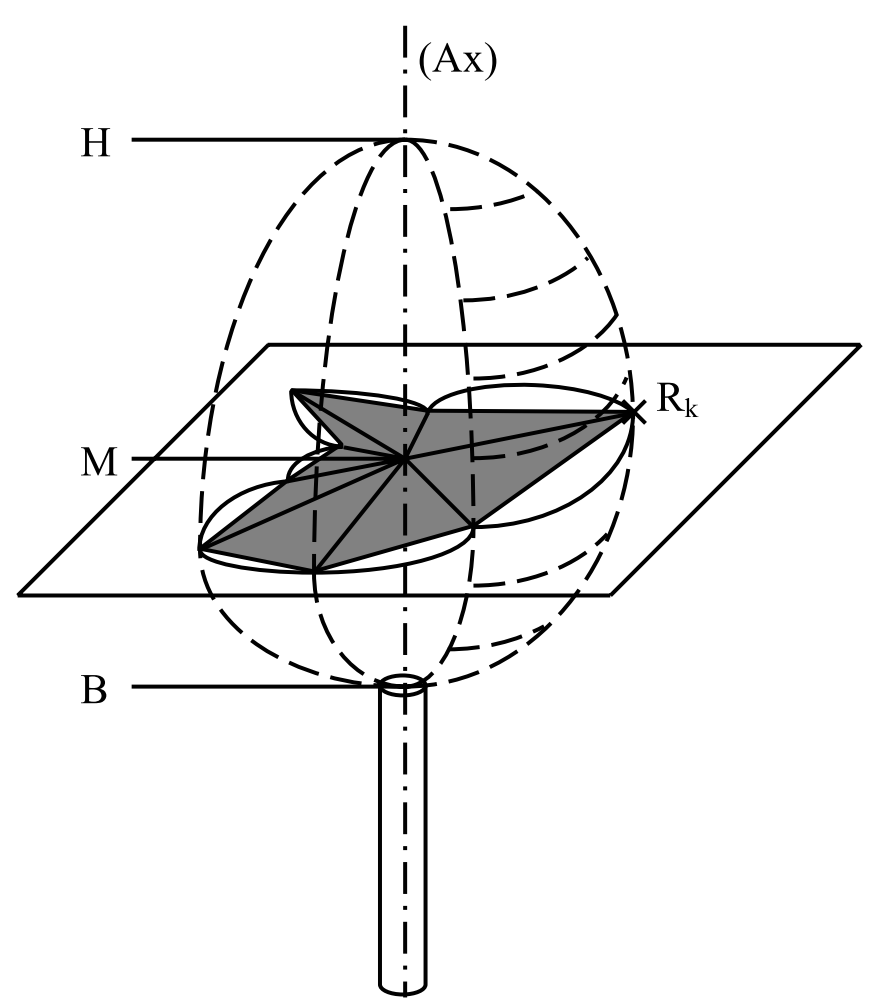

Figure 3. Tree representation in the tRAYci model. The stem is represented by a cylinder. $(A x)(-\cdot-\cdot)$ is the vertical axis passing through the stem centre. $H, B$ and $M$ are points on this axis, corresponding to total tree height, crown base height and height of maximum crown width, respectively. $R k$ is one of the eight radii $R i$ ( $i$ from 1 to 8 , in solid lines (- - ), describing the projection of the crown in the horizontal plane passing through point $M$. This projection is the grey area. The geometrical volume of crowns used in tRayci is obtained by the broken lines (- - ) linking the $R i$ to $H$ and $B$. The volume outline in the horizontal plane passing through $M$ is delimited by solid lines ( - ); it is composed of ellipse-sectors between successive radii.

projected at ground level and which made it possible to take the main crown irregularities into account. The position (distance and azimuth) of each point relative to the crown centre was then measured.

For stem clumps, a single crown for each clump was considered, except if one stem was clearly isolated from the others. In this case the stem was excluded from the clump and measured as an individual tree (with an individual crown). In the study areas and first buffers pooled, a total of 1182 and 177 crowns corresponding to 1589 and 227 stems were measured in Plots 1 and 2, respectively.

In the second buffers, the same set of variables, except the crown variables, was measured. A total of 879 and 280 stems were measured in the second buffers of Plots 1 and 2, respectively.

We thus measured a total of 2975 stems and for 1816 of these stems (study areas and first buffers), we measured a total of 1359 crowns (Fig. 2b).

\subsubsection{Simulation plot used for light simulations}

TRAYci was used to simulate PACL in the study areas. The goal of the first and second buffers is to provide the necessary edge for light simulations. The crowns of the trees in the first buffers are measured exactly as in the study area. The crowns of the trees located in the second buffers, where only stems were measured, have a smaller impact

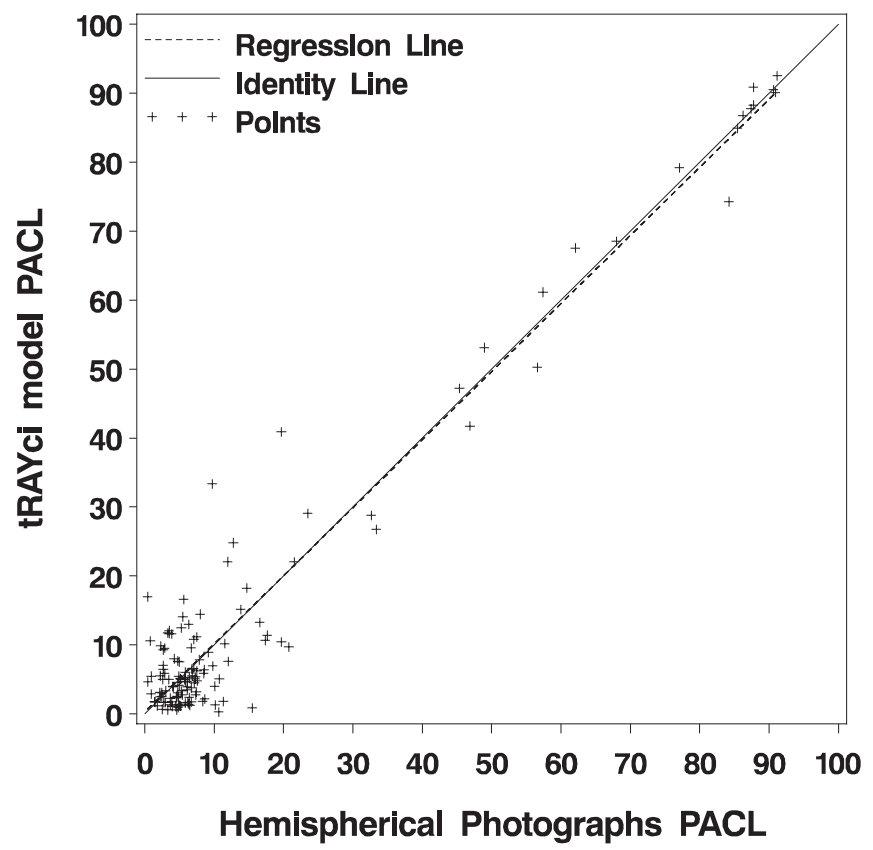

Figure 4. Linear regression between PACL values simulated by the tRAYci model for $L A D=1.6 \mathrm{~m}^{2} \cdot \mathrm{m}^{-3}$, versus PACL values obtained from hemispherical photographs. Linear regression model $(n=137$, $\left.R^{2}=0.95\right):$ PACL $_{\text {tRAYci }}=0.978711 \cdot$ PACL $_{\text {hemispherical photographs }}+$ 0.24456 . The regression line is not significantly different from the identity line $(p=0.8187)$.

on light simulation achieved in the study area and are thus modelled with a lower precision and reconstructed using the CROM algorithm.

The two plots were included in an 18.72 ha rectangular plot for light simulations. A remote realistic forest ambiance was recreated in the empty areas of the rectangular simulation plot as follows (Fig. 2c). A closed stand was generated using the stem diameter and species distributions from measured areas. The obtained stems were randomly positioned and then repositioned by a regularisation procedure in order to avoid aggregations and gaps. Crowns were reconstructed using the CROM algorithm and gaps were created based on aerial photographs of the site. In order to simulate forest influence further away, a tRAYci option that replicates the rectangular simulation plot all around itself was used.

\subsubsection{Species-level parameter determination}

The mean height of maximum crown width (relative to crown length) was calculated for each species from individual tree values and used for simulations. A value of 2 was arbitrarily used for the upper and lower shape parameter, making the CROM algorithm possible because of the relative simplicity of the quarter ellipse formula. The upper and the lower shell thickness parameter were arbitrarily fixed at $100 \%$ and $0 \%$, respectively. We therefore did not consider leaf aggregation in the crown periphery. The $L A D$ was the only calibrated parameter.

A unique $L A D$ value was used for all species due to the difficulty of establishing species values on the considered study site. Thus, this paper does not focus on leaf distribution in the crown. The consequences of this choice will be discussed. A series of simulations was made to determine which $L A D$ values provided the best correlation (unbiased, closest as possible to the identity line) between simulated 
Table I. Regression results of the diameter-related allometric relations for each species. In the equations, $d$ is the diameter at $1.30 \mathrm{~m}$, expressed in centimetres. $\left(\mu_{1}, \mu_{2}, \mu_{4}\right),\left(\alpha_{\mathrm{L}}, \beta_{\mathrm{L}}\right)$ and $\left(\alpha_{\mathrm{R}}, \beta_{\mathrm{R}}\right)$ are the parameter estimates of the total height, crown length and crown equivalent radius models, respectively. $N$ is the number of observations and $R^{2}$ is the coefficient of determination: $R^{2}=1-$ (residual sum of squares)/(corrected total sum of squares).

\begin{tabular}{|c|c|c|c|c|c|c|c|c|c|c|c|}
\hline \multirow[b]{3}{*}{ Species } & & \multicolumn{4}{|c|}{ Total height $(H$ in $\mathrm{m})$} & \multirow{2}{*}{\multicolumn{3}{|c|}{$\begin{array}{c}\text { Crown length }(L \text { in m) } \\
L=\alpha_{L} \cdot d+\beta_{L}\end{array}$}} & \multirow{2}{*}{\multicolumn{3}{|c|}{$\begin{array}{c}\text { Crown equivalent radius ( } R \text { in } \mathrm{m}) \\
R=\alpha_{R} \cdot d^{2}+\beta_{R} \text { for beech, } \\
R=\alpha_{R} \cdot d+\beta_{R} \text { for others. }\end{array}$}} \\
\hline & & \multicolumn{4}{|c|}{$\begin{array}{c}H=\frac{\alpha-\sqrt{\alpha^{2}-4 \mu_{2} \mu_{4}\left(\mu_{1}-1.3\right) \cdot d}}{2 \mu_{4}}+1.3 \\
\alpha=\mu_{1}-1.3+\mu_{2} \cdot d *\end{array}$} & & & & & & \\
\hline & $N$ & $\mu_{1}$ & $\mu_{2}$ & $\mu_{4}$ & $R^{2}$ & $\alpha_{L}$ & $\beta_{\mathrm{L}}$ & $R^{2}$ & $\alpha_{R}$ & $\beta_{\mathrm{R}}$ & $R^{2}$ \\
\hline Beech & 103 & 30.620 & 1.225 & 0.551 & 0.916 & 0.138 & 5.941 & 0.614 & 0.00101 & 2.410 & 0.905 \\
\hline Hornbeam & 818 & 23.285 & 1.199 & 0.812 & 0.727 & 0.169 & 3.989 & 0.305 & 0.07840 & 1.001 & 0.619 \\
\hline Sycamore & 47 & 32.194 & 1.607 & 0.139 & 0.818 & 0.174 & 3.539 & 0.413 & 0.07950 & 0.697 & 0.814 \\
\hline Norway maple & 20 & 31.133 & 1.950 & 0.139 & 0.930 & 0.166 & 4.409 & 0.860 & 0.06340 & 1.390 & 0.855 \\
\hline Field maple & 114 & 24.020 & 1.065 & 0.857 & 0.837 & 0.170 & 3.555 & 0.446 & 0.04370 & 1.251 & 0.523 \\
\hline Wild service tree & 39 & 21.026 & 1.307 & 0.745 & 0.842 & 0.213 & 1.855 & 0.554 & 0.04690 & 1.037 & 0.524 \\
\hline White beam & 56 & 19.903 & 1.111 & 0.960 & 0.838 & 0.170 & 2.762 & 0.295 & 0.06720 & 0.737 & 0.579 \\
\hline Lime & 62 & 25.504 & 1.046 & 0.788 & 0.768 & 0.140 & 4.834 & 0.362 & 0.05930 & 1.393 & 0.760 \\
\hline Oak & 80 & 21.668 & 1.223 & 0.846 & 0.209 & 0.116 & 3.407 & 0.211 & 0.08520 & -0.044 & 0.662 \\
\hline
\end{tabular}

* Equation from [26].

PACL values and PACL values obtained from the 137 hemispherical photographs. $L A D$ values from 0.1 to $10 \mathrm{~m}^{2} \cdot \mathrm{m}^{-3}$ were tested. For each simulation, a linear least square regression was fitted between tRAYci and hemispherical photograph PACL values, using the REG procedure of the SAS/STAT software [56]. The best fit (Fig. 4) was obtained for a $L A D$ of $1.6 \mathrm{~m}^{2} \cdot \mathrm{m}^{-3}$. $R$-square was 0.945 and the model was not significantly different from the model of slope equal to 1 and intercept equal to 0 ( $p$-value of 0.82 , obtained by REG/TEST statement).

\subsection{Allometric relations for crown variables}

Crown variables required by tRAYci for each tree were total tree height, crown base height and crown radii. Allometric relations were developped to relate these variables to stem diameter.

We directly predicted total height from stem diameter.

Crown base height $\left(H_{B}\right)$ may be expressed as follows:

$$
H_{B}=H-L
$$

where $H$ is total height and $L$ is crown length. Considering that crown base height strongly depends on total height, we used crown length instead of crown base height to be predicted from stem diameter.

The crown shape of individual trees (defined by the eight crown radii) was obtained with reconstruction algorithms. The algorithms require the equivalent crown radius for each tree, defined as the radius of a circle whose area is equal to the crown area at the height where radii are measured (i.e., the height of maximum crown width). The equivalent radius was predicted from stem diameter.

For each variable and for each species, allometric relations were established with stem diameter as the independent variable. For clumps (a single crown was considered for each clump), we used the following to calculate stem diameter:

- The max stem diameter of the clump, for prediction of total height and crown length.

- The equivalent stem diameter, calculated as the diameter of a stem whose basal area was the sum of the basal areas of all the stems of the clump, for prediction of equivalent crown radius.

Relationships were established using SAS/STAT software [56] with data from the completely measured trees (study areas and first buffers, 1359 crowns). Equations, parameters and coefficients of determination are given in Table I. The SAS/STAT/NLIN procedure was used for total tree height and the SAS/STAT/REG procedure for crown length and equivalent crown radius.

Relationships between total height and diameter were very significant for all species. $R^{2}$ (coefficient of determination) was good for beech, maples, wild service tree and white beam, ranging from 0.818 to 0.916 (Tab. I). For hornbeam and lime, relations were more dispersed with $R^{2}$-values of 0.727 to 0.768 , respectively. This was probably due to the coppice stems in these species that increased variation among trees: some coppice stems were completely dominated while other stems had reached the dominant or co-dominant strata. $R^{2}$-values for oaks were relatively low, probably because of the small number of oak trees present in the stand, and the low vigour of these trees.

Relationships between crown length and diameter were also highly significant for all species but showed a large variation: $R^{2}$-values ranged from 0.211 to 0.860 but were mostly below 0.60 , revealing high variability of crown length among the trees. Coppice species such as hornbeam, lime and white beam showed a particularly high variability, with $R^{2}$-values of $0.305,0.362$ and 0.295 , respectively.

Relationships between equivalent crown radius and diameter were highly significant for all species, with $R^{2}$-values ranging from 0.523 to 0.855 .

\subsection{Crown reconstruction algorithms}

Two algorithms were developed to reconstruct crown radii for each tree from tree position, stem diameter, total tree height, crown base height and equivalent crown radius. The three latter variables were predicted from diameter by species-specific allometric relations, as seen before. The first algorithm is the isotropic crown reconstruction algorithm. This simple approach gives only one constant radius for a crown, equal to its equivalent crown radius. The second is the Crown Reconstruction by Overlap Minimisation algorithm where crowns are asymmetrically expanded. In both cases, total height and crown base height are constant, and the tRAYci geometry is used. The difference between the two methods lies in crown lateral extension (crown radii) reconstitution. 


\subsubsection{Isotropic crown reconstruction algorithm}

In this method, all radii of a crown are considered to be equivalent and have the same length, $r$, the equivalent crown radius. The crown is constituted of two half-ellipsoids (for upper and lower crown sections, respectively) and its volume $(V)$ is given by:

$$
\frac{1}{2} \cdot \frac{4 \pi}{3} \cdot r^{2} \cdot k \cdot L+\frac{1}{2} \cdot \frac{4 \pi}{3} \cdot r^{2} \cdot(1-k)
$$

where $L$ is the predicted crown length, $k$ is the proportion of $L$ above the height of maximum crown width and $r$ is the equivalent crown radius.

\subsubsection{Crown Reconstruction by Overlap Minimisation algorithm}

The tRAYci crown geometry is used in the CROM algorithm, which was developed in Java language (Sun Microsystems Inc., Santa Clara, CA, USA) under the CAPSIS 4 project $[24,25]$ and independently of tRAYci software.

A target volume is defined for each crown, calculated from crown length and equivalent crown radius as was done in the isotropic algorithm, equation (2). Each crown is limited at the top by total height and at the bottom by crown base height. Its lateral extension is defined in a horizontal plane at a height of maximum crown width by $n$ radii. In the algorithm, $n$ is first equal to 32 radii regularly spaced in all directions. At the end of the algorithm this number is reduced to eight with an angle between two adjacent radii always less than $90^{\circ}$, in accordance with tRAYci specifications. At all heights between crown base height and total height, the crown is constituted in a horizontal plane by $n$ ellipse sectors. Each ellipse sector is delimited by two sides and one elliptical curve. The lengths of the two sides are related to corresponding radii - which are defined at the height of maximum crown width and parallel to these sides - by the quarter ellipse formula.

The CROM algorithm is based on five principles:

- Each crown finally reaches its target volume;

- Total tree height and crown base height parameters are fixed for each tree and only the crown radii can be adapted to reach the target volume, under a user-defined maximum-allowed asymmetry condition;

- Trees with a large stem diameter have priority over smaller trees for space occupation;

- Each tree has a minimum crown volume (determined by its diameter), which limits the development of other crowns, even of larger trees;

- Crown overlap is minimised as much as possible by crown asymmetry, and is allowed if a crown needs to expand while no more space is available and target volume has not been reached.

These principles correspond to a set of assumptions about crown development and inter-tree competition in broadleaved forest stands:

- We assumed that the plasticity of trees is mostly generated by lateral crown extension. Vertical plasticity (vertical crown depth) has also been shown [29], particularly near large gap edges [47], but lateral extension plasticity is considered here to have the major influence and to compensate for a possible underestimation of vertical plasticity. In the present study vertical plasticity is not considered.

- We assumed that dominant trees have more isotropic crown than dominated ones.

- We assumed that trees avoid overlapping crowns with neighbouring trees and are able to adjust the horizontal shape of their crown in response to neighbour competition and extend their crown into available space $[47,48]$. Plasticity differences in species under competition were not considered here, although it has been demonstrated by Frech et al. [29].
The algorithm uses the following input parameters:

- $d H$ is the vertical distance between two successive horizontal planes where overlaps between crowns are evaluated. It should be as small as possible but excessively small values would considerably increase computation time. In our simulations we used a value of $2 \mathrm{~m}$.

- $d R$ is the length by which radii are increased at each iteration of each individual crown reconstruction loop. It should be as small as possible but excessively small values would considerably increase computation time. In our simulations we used a value of $0.5 \mathrm{~m}$.

- $K r$ is the minimum radius coefficient. The minimum and irreducible radius $R m(\mathrm{~m})$ of a crown is defined as follows: $R m=K_{2} \cdot 2$, where $d$ is the diameter $(\mathrm{m})$ of the crown stem. In our simulations we used a value of 2 for $K r$.

- $A F$ is the maximal allowed asymmetry factor. It defines the asymmetry condition as follows: at the end of each iteration, each radius $r$ of the reconstructed crown must satisfy the equation, $r \leq A F \cdot R_{e q}$, where $R_{e q}$ is the radius of a circle whose area is equal to the present crown area, at the height of maximum crown width. In our simulations we used a value of 2 for $A F$.

- Rmax is the absolute maximum crown radius allowed. This is a crown extension limitation parameter, which should be relatively high. In most cases, $A F$ factor would act before Rmax. In our simulations we used a value of $20 \mathrm{~m}$ for Rmax.

The algorithm is divided into five main steps (Fig. 5).

Step 1: Minimal crown creation. Each crown is initialised as a set of 32 regularly-spaced radii (angle of $11.25^{\circ}$ between two successive radii), with a radius length established at a starting value $R m$, depending on the $K r$ coefficient and stem diameter. The number of radii (32) is chosen to allow good crown shape plasticity without increasing the computation time too much. At this stage, overlaps between crowns are negligible if $K r$ is established at a reasonable value (not too high).

Step 2: Crown expansion. Crowns are treated successively in decreasing order of stem diameter at $1.30 \mathrm{~m}$. For each crown, the following sub-steps are taken. (2.a) Neighbours are searched within a specified radius (equal to Rmax) from stem position. (2.b) A series of height levels $(h)$ are defined from the height of maximum crown width (Hm) to both crown base height (downwards) and total height (upwards). The vertical distance between two successive height levels is $d H$. Thus, for each height level $h$, we can write $h=H m \pm k \cdot d H$, where $k$ is an integer. (2.c) For each height level $h$, crown sectors are computed and stored for each neighbour. (2.d) A "radii expansion loop" is launched. Before the first iteration, all radii values are set at "allowedto-expand". The radii expansion loop continues while there is at least one allowed-to-expand radius, and crown volume is smaller than the target volume. At each iteration of the radii expansion loop, the following phases are completed. (2.d.i) All allowed-to-expand radii are increased by $d R$. If any radius exceeds Rmax or violates the asymmetry condition (see $A F$ description above), its increase is cancelled and it is removed from the allowed-to-expand radii list. (2.d.ii) For each height level $h$, crown sectors at height $h$ are computed and stored for the considered crown, according to the new radii size. (2.d.iii) For each pair of successive radii of the considered crown, all intersections between the ellipse sectors based on these two radii - one sector per height level - and all ellipse sectors of neighbour crowns are computed, for all height levels. If any intersection is found, increases of the two concerned radii are cancelled (if they were allowed-toexpand), and they are removed from the allow-to-expand list. Each intersection test is thus computed in a horizontal plane (at the considered height level) between two ellipse-sectors, one from the considered crown and one from a neighbour crown. The overlaps between crown $3 \mathrm{D}$ volumes are thereby evaluated by a set of $2 \mathrm{D}$ intersections between horizontal crown slices regularly spaced along vertical crown length and centred on a height of maximum crown width. It must be noted that height levels are defined separately for each expanded crown. Thus, depending on the currently expanded crown, a given crown - viewed as a neighbour - is not considered at the same height 


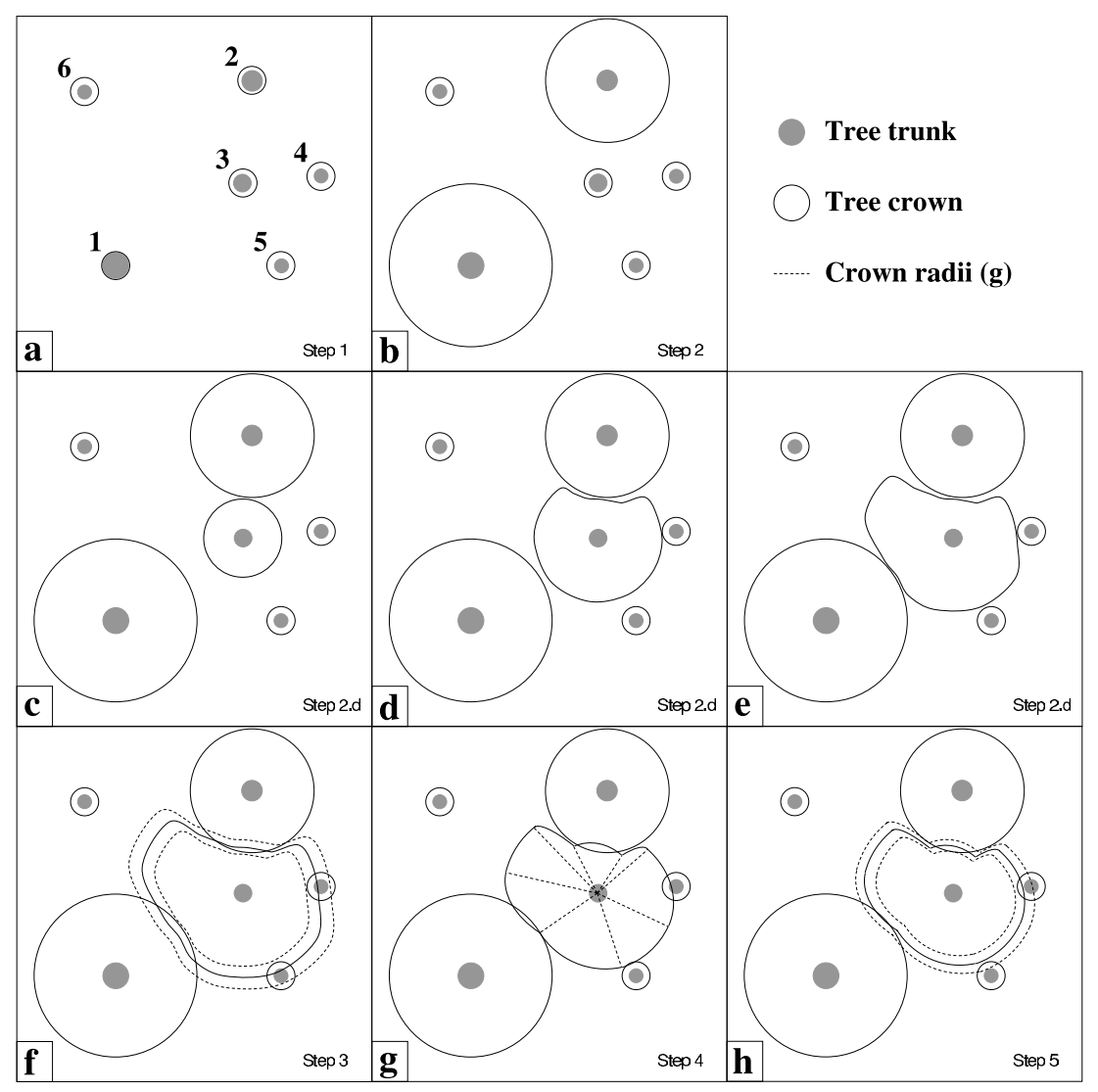

Figure 5. Some steps of the Crown Reconstruction by Overlap Minimisation algorithm at the stand scale. The example shown is simplified: all intersections are considered at the same height. Trees are numbered and treated in decreasing diameter size. (a) A minimal crown has been created for each tree. (b) Tree No. 1 and No. 2 crowns have reached (and slightly exceeded) their target volume. (c) (d) The radii of tree No. 3 has increased while not overlapping neighbours and target volume is not reached. (e) The crown of tree No. 3 either has reached and slightly exceeded target volume during the last loop iteration or cannot expand anymore without overlapping its neighbours: crown expansion stops. (f) (h) For each tree, crown radii are adjusted in order to exactly reach target volume. Boundary volumes of the adjustment (broken lines) are exaggerated on the figure. (g) The number of radii is reduced to eight for each tree; the radii of tree No. 3 are shown in broken lines.

levels. At the end of this step, there is no overlap between crowns except those resulting from Step 1, and two types of crowns may be distinguished: crowns with a volume below the target volume which cannot expand anymore without overlapping or exceeding Rmax, and crowns with a volume equal to or slightly above the target volume.

Step 3: First volume correction. (3.a) Expansion of crowns with a volume below the target volume. These crowns cannot reach the target volume without overlapping other crowns or exceeding Rmax. These crowns are expanded using a loop structure. At each iteration, all radii are increased by $d R$ (except if the resulting length exceeds $R \max$ ). The loop is stopped when the target volume is reached or just exceeded. At the end of this sub-step, every crown has a volume above or equal to its target volume. For these crowns, overlap with neighbours cannot be avoided to reach target volume. (3.b) Reduction to the exact target volume. After (3.a), all crowns have a volume above or equal to target volume and had a volume below the target volume before last radii expansion. Thus, the target volume is included in the interval limited by the two situations: before and after last radii expansion (during either Step 2 or Step (3.a). A loop is used to converge to the target volume. At each iteration, radii are adjusted to the intermediate situation between the two previous ones, splitting the volume interval into two parts. The part containing the target volume is established as the new interval, and a new iteration begins. This type of loop, more generally known as a "dichotomy" procedure, quickly converges. At the end of this step, each crown has reached exactly its target volume, due to adjustment of all its radii by a common length (smaller than $d R$ ).

Step 4: Reduction of the number of radii. Thirty-two radii per crown were used in previous steps to allow for sufficient shape plasticity. This number has to be reduced to eight for compatibility with tRAYci. A loop is used to remove the less useful radii. At each iteration, remaining radii are sorted by the absolute variation in crown volume, which would come from their suppression, and for each radius, the angle between its two neighbour radii is stored. The least influential radius on crown volume whose neighbour radii are not separated by more than $90^{\circ}$ is removed. The loop stops when only eight radii remain. At the end of this step, all crowns are represented by eight radii.

Step 5: Second volume correction. Step 4 can create a small deviation in crown volume that needs to be corrected. The method used is the same as in Step 3 except for the initial interval. To obtain it, we first determine if volume is below or above target volume. Next, radii are respectively increased or decreased by $d R$ successive units until reaching a second boundary with a volume above or below target volume. At the end of this step, all crowns are defined by eight radii and have a volume equal to their target volume.

\section{6. tRAYci validation and evaluation of crown reconstruction methods}

First, a reference light simulation was made using all measured data. The simulation was used to validate the model tRAYci for our study site, against the 37 light sensors.

Second, we simulated PACL in four reconstructed stands, resulting from interaction of two factors:

- The reconstruction algorithm used either an "isotropic" or an "anisotropic" (CROM) algorithm.

- The crown centre used either a measured "crown" centre or a measured "stem" centre for crown reconstruction. Indeed, the position of the crown centre directly influences its extension possibilities. The "crown" centre is more realistic, but the "stem" centre is much easier to measure in the stand. 


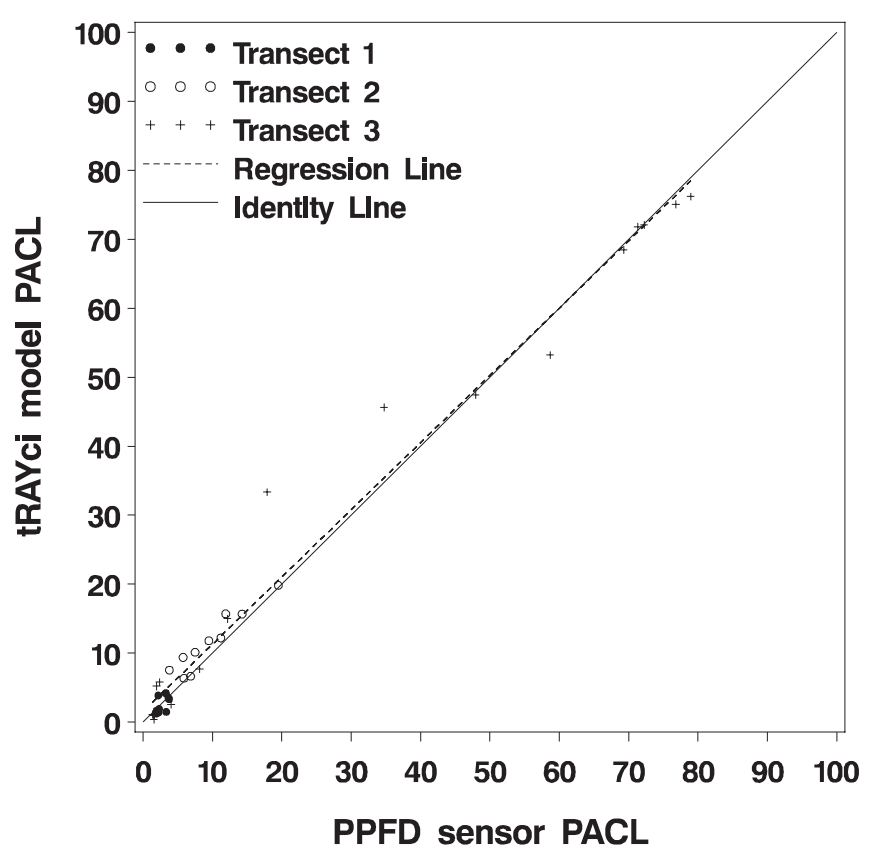

Figure 6. Linear regression between PACL values simulated by the tRAYci model versus PPFD sensor PACL values, for each sensor position (by sensor transect). Linear regression model $\left(n=37, R^{2}=\right.$ 0.98): PACL $_{\mathrm{tRAYci}}=0.97456 \cdot \mathrm{PACL}_{\mathrm{PPFDsensor}}+1.51618$. The regression line is not significantly different from the identity line ( $p=$ $0.1277)$.

The simulated PACL values were compared to PACL values measured in the field by the light sensors, using the SAS/STAT/REG procedure. For all simulations (the measured stand and the four reconstructed stands), a single period was used, equal to the measurement period (June 25 to August 2, 2004). The measured PDIF value (45.84\%), a Standard Overcast Sky Condition diffuse distribution (with a coefficient $b$ of 1.23), a ray resolution of 1 degree and a cellgrid width of $0.2 \mathrm{~m}$ were used. The cosine correction option was used because of comparisons with plane sensors.

\section{RESULTS}

\subsection{Model validation by light sensors}

The tRAYci light simulation values obtained with the completely measured stand data were compared to light values measured using light sensors (Fig. 6). The linear regression model is highly significant ( $p$-value $<0.0001$ ), not significantly different from the identity line $(p$-value $=0.12)$ and $R^{2}$ is high with a value of 0.98 . A good agreement between model predictions and light measurement was observed. Visually, values in Transect 2 seem to be slightly overestimated, probably due to the inaccurate representation of some crowns.

\subsection{Light simulations obtained with reconstructed stands}

Figure 7 shows simulated as opposed to measured PACL values for the four crown reconstruction simulations. Simula- tions with the isotropic crown reconstruction method (Figs. 7a and $7 \mathrm{~b}$ ) showed a statistically significant ( $p$-value $<0.0001$ and $R^{2}>0.97$ ) but clearly biased relation with sensors. Indeed, the regression line is significantly different from the identity line ( $p$-value $<0.0001)$. The simulated PACL was always overestimated. The bias was larger for low PACL values, particularly for PACL below $25 \%$.

The use of the anisotropic algorithm strongly reduces this bias (Figs. 6c and 6d). In the case where stem centre was used ( $p$-value $<0.0001, R^{2}=0.98$ ), even if the bias was considerably reduced compared with the isotropic simulation, it is already present and significant, caused by points for measured PACL values below $10 \%$ (the regression line is significantly different from the identity line, $p$-value $<0.0001$ ).

But the use of crown centre in conjunction with the anisotropic approach leads to a very good relation without any clear bias: the relation is significant $(p$-value $<0.0001)$ and good $\left(R^{2}=0.99\right)$. The regression line is very close to the identity line, even if these two lines remain statistically significantly different at a $5 \%$ level $(p$-value $=0.02)$.

\section{DISCUSSION}

The tRAYci model was validated at the study site against PAR sensors, using the complete measured data set. The results were good, indicating that this model can be used for predicting light in irregular mixed broadleaved forests, and legitimating our approach consisting in reducing the number of input data. The validation was made on a large range of measured PACL values, ranging from $1.33 \%$ to $79.70 \%$, including very closed stand areas, small gaps and a large gap. However, less points were sampled for PACL between $20 \%$ and $70 \%$, despite a fine sampling of light gradients on the measurement transects. This was due to two reasons: (i) medium-sized gaps (area of 0.20.4 ha, in which this range of PACL values would have been more common) were not present at the study site; and (ii) this range of PACL values corresponded to the stand edge in Plot 2, where the light gradient was the greatest, reducing the area where these PACL values were present.

The isotropic method for crown reconstruction was very attractive because of its simplicity, but results showed that it resulted in a large overestimation bias, particularly evident for measured PACL values below 25\%. This effect may be explained by geometrical considerations: real tree crowns are asymmetrical to varying extents. An isotropic reconstruction leads to overlaps between crowns, resulting in an underestimation of the space occupied by crown volumes, and consequently to an overestimation in understory PACL estimation. Excessive overlaps, resulting from the use of an isotropic shape for modelling asymmetrical shapes, have also been demonstrated in root ecology [4]. Moreover, the lowest PACL values corresponded to areas with a closed canopy, where trees were highly constrained by the high density, and the bias related to overlap increase was higher because most trees were tilted or had highly asymmetric crown shapes, due to strong competition. The bias is closely related to local canopy structure and it would be difficult to correct it systematically. 

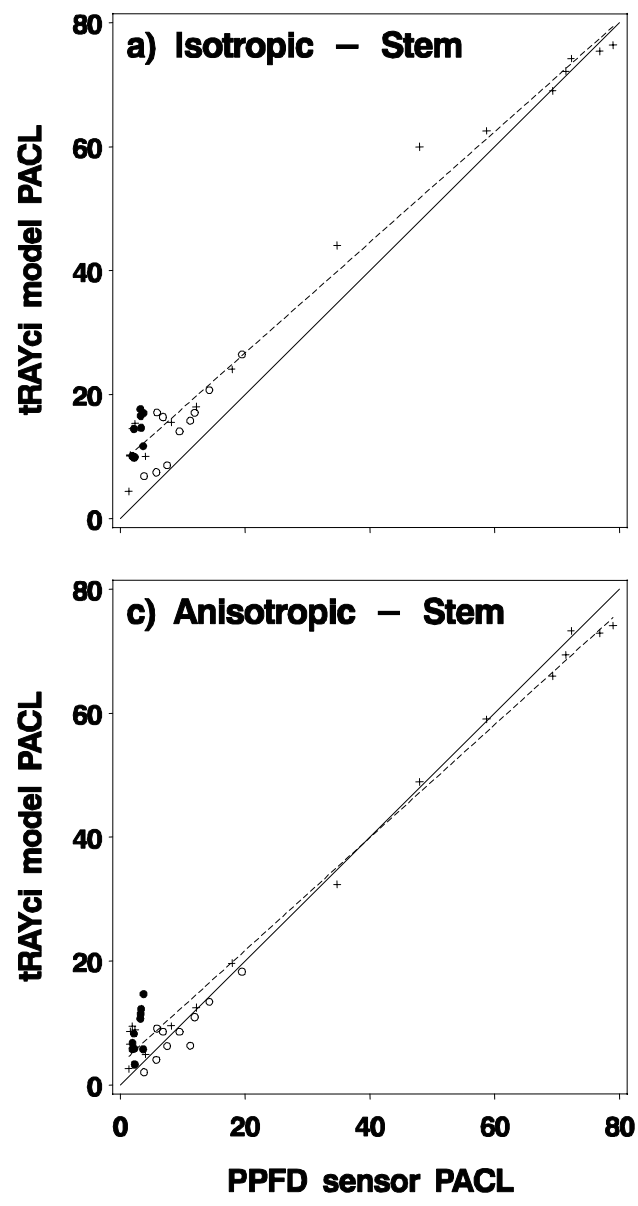
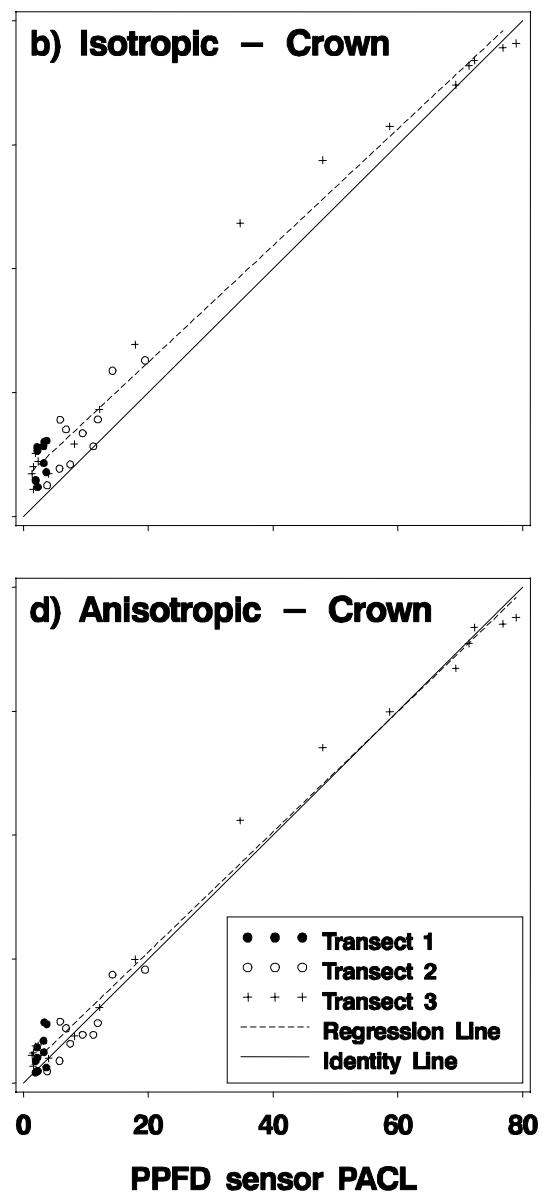

Figure 7. PACL simulated by the tRAYci model versus PPFD sensor PACL value, after isotropic crown reconstruction (a and b) or Crown Reconstruction by Overlap Minimisation (c and d). In (a) and (c), crowns are reconstructed from stem positions. In (b) and (d), crowns are reconstructed from measured-crown centre positions.
The CROM method, consisting of minimising overlaps when reconstructing crowns, solves this problem. Some bias is still present in closed canopy areas where crowns are completely off-centre in relation to stem position, when using the stem position for crown reconstruction. The anisotropic approach has the advantages of asymmetrical crown modelling, without actually measuring this asymmetry, saving much time in the field. The main assumption made is that the actual shape of the crowns is not needed but only an adequate distribution of crown volumes at the local canopy scale.

We showed that using the position of the crown centre instead of the stem position in combination with the CROM method completely avoids the bias, even in closed canopy areas. This involves measuring the crown centre in the field, a limitation to our simplification approach. However, considering the CROM principles, high precision is probably not necessary when evaluating crown centre because the bias mainly arises when the crown centre is far away from the stem. An efficient method for field measurement could be to use stem position for the majority of trees and to visually estimate a crown centre for trees that clearly have off-centre crowns (when stems are at the very edge or outside of the crown). We observed the bias mainly in locally dense areas, where intense inter-tree competition brought about major constraints on tree growth. Thus, it will probably not occur in regularly thinned stands, where competition is regularly reduced. In the study site, the presence of an old coppice growing up between reserve trees undoubtedly increased crown eccentricity.

The advantage of the CROM method compared with isotropic methods depends on the context. The main disadvantage of the isotropic method is its poor representation of the canopy when trees are very asymmetrical. Thus, for stands where crowns are relatively symmetrical, this method could be sufficient. This occurs either in stands with low competition among trees, such as sparse even-aged stands, or for species with small crown lateral plasticity, such as most conifers (i.e., Douglas fir, spruce).

The crown asymmetry is determined by the potential crown plasticity of the trees and the degree of inter-tree competition. The potential crown asymmetry probably depends on the species [29]. Thus, the CROM algorithm could be improved by using species-specific asymmetry factors, instead of a single value for all trees. The modelling of vertical plasticity for the crown could also be developed. In the CROM algorithm, crown asymmetry is simulated from tree positions and diameter at a given time. This is sufficient to obtain a good representation of $3 \mathrm{D}$-space occupation by crown volumes at the local canopy scale in order to simulate understory light regime, but it is not intended for realistic individual crown modelling. Indeed, past 
interactions between trees are unknown but would be necessary to simulate real crown development and, thus, their exact shape and space localisation. We have focused on obtaining a good spatial distribution of the total crown volume at a local scale and have not validated our approach by directly comparing modelled crowns to real ones, and only tested if the simulated stands with reconstructed crowns gave good results in the light model. An approach similar to the CROM algorithm has been proposed by Grote [32] in which potential crown radius is predicted from stem diameter without using crown volume, and by managing overlaps in a simpler way than in the CROM algorithm. In this work, validation is made in terms of crown geometry and shows a strong correlation of crown projection areas with measured ones but poor prediction for particular radii.

The bias caused by the isotropic method is mainly present for PACL values below 25\%. Thus, its importance depends on whether these PACL values are of interest for the processes studied. In tRAYci, the considered spectrum is the PPFD, which is mainly used for studying plant growth, and particularly for analysing forest regeneration growth. In this case, it is particularly crucial to be accurate in PACL estimation below $25 \%$ [27, 62], making simulation improvements obtained by the use of CROM algorithm very significant.

Shape, shell thickness and $L A D$ parameters influence the total amount of leaves on each tree. Thus, they strongly interact in light prediction. For computational reasons in the CROM algorithm (particularly crown volume calculation), the shape parameter was set at a "simple" value, 2, corresponding to ellipsoid-like shapes. This assumption seems visually well adapted for broadleaves. It could be problematic for some conifers (such as Douglas fir or spruce for example), but the algorithm can easily be adapted to conical-like shapes (parameter equal to 1). Only $L A D$ was adjusted, considering that its calibrated value would compensate for inaccuracy in shape parameters. These parameters were adjusted for all species pooled. Gersonde et al. [30] showed that using species-specific values instead of individual values leads to negligible decline in light predictions. We decided to consider a common value for all species because the species present on the study site seemed to have similar $L A D$ (no apparent light-foliage species were present, such as ash or birch). Simulation results indicated that a constant $L A D$ value for all species could be used at our study site. In stands with others characteristics - especially in stands containing species with contrasted foliage density - it could be necessary to use species-specific $L A D$ values to obtain unbiased light prediction. However, we already mentioned the difficulty in studying $L A D$ distribution in vertically or/and horizontally heterogeneous stands. In particular, it should be considered that the $L A D$ parameter of light models is strongly dependent on the geometry used to describe crown shape, and may be very different from $L A D$ values measured in the field by considering leaf area.

In this study, light was always simulated near ground level. When estimating PACL higher up in the canopy (i.e., closer to the crowns), results may be less accurate because the exact position of the crown may be more influential closer to the crowns. In [5], a greater mean deviation of the tRAYci model versus hemispherical photographs was found for points in the upper canopy. It is, however, difficult to predict if (and how much) crown reconstruction increases this effect. This should be tested before crown reconstruction is used to simulate light higher up in the canopy.

Another important fact is that the algorithms were tested in a single stand. The stand was well adapted to the CROM algorithm test because of particularly important asymmetry among trees, due to the old coppice-with-standards structure of the stand and the presence of gaps. Further validations in other stand types should be made to compare and validate the crown reconstruction algorithms.

In this study, we presented an efficient way to use complex and accurate light models with a reduced number of measured data. This approach can be used to predict light in field studies while saving a lot of measurement time. A second application of the crown reconstruction algorithms is their potential use with stand growth simulators to obtain PACL distribution within the simulated stand. These algorithms could be used with any spatially explicit growth model that simulates stem diameter, provided that crown volume-diameter allometric relations were established for the considered tree species. Finally the isotropic and CROM algorithms were used in combination with tRAYci, but their outputs may be used with any light model using crown radii, total height and crown base height for crown representation.

Acknowledgements: We would like to thank Bruno Garnier, Michel Pitsch and Léon Wehrlen for assistance in the field. We would also like to thank Andreas Brunner for his assistance and advice on the tRAYci model and for his helpful review of this article. We are grateful to the Office National des Forêts for its financial contribution to this work and for allowing us to work on the study site. We thank François Ningre and the anonymous reviewers for their helpful comments.

\section{REFERENCES}

[1] Bartelink H.H., MAPFLUX: a spatial model of light transmission through forest canopies, report No. 15, Department of Forestry, Agricultural University, Wageningen, Netherlands, 1995, 31 p.

[2] Bégué A., Prince S.D., Hanan N.P., Roujean J.L., Shortwave radiation budget of Sahelian vegetation. 2. Radiative transfer models, Agric. For. Meteorol. 79 (1996) 97-112.

[3] Berbigier P., Bonnefond J.M., Measurement and modelling of radiation transmission within a stand of maritime pine (Pinus pinaster), Ann. For. Sci. 52 (1995) 23-42.

[4] Brisson J., Reynolds J.F., The effect of neighbors on root distribution in a creosotebush (Larrea-Tridentata) population, Ecology 75 (1994) 1693-1702.

[5] Brunner A., A light model for spatially explicit forest stand models, For. Ecol. Manage. 107 (1998) 19-46.

[6] Brunner A., Nigh G., Light absorption and bole volume growth of individual Douglas-fir trees, Tree Physiol. 20 (2000) 323-332.

[7] Canham C.D., An index for understory light levels in and around canopy gaps, Ecology 69 (1988) 1634-1638.

[8] Canham C.D., Denslow J.S., Platt W.J., Runkle J.R., Spies T.A., White P.S., Light regimes beneath closed canopies and tree-fall gaps in temperate and tropical forests, Can. J. For. Res. 20 (1990) 620-631.

[9] Canham C.D., Coates K.D., Bartemucci P., Quaglia S., Measurement and modelling of spatially explicit variation in light transmission through interior cedar-hemlock forests of British Columbia, Can. J. For. Res. 29 (1999) 1775-1783. 
[10] Cescatti A., Modelling the Radiative transfer in discontinuous canopies of asymmetric crowns. I. Model structure and algorithms, Ecol. Model. 101 (1997) 263-274.

[11] Chartier M., Bonchretien P., Allirand J.M., Gosse G., Utilisation des cellules au silicium amorphe pour la mesure du rayonnement photosynthétiquement actif (400-700 nm), Agronomie 9 (1989) 281-284.

[12] Chelle M., Andrieu B., Radiative models for architectural modeling, Agronomie 19 (1999) 225-240.

[13] Chen S.G., Ceulemans R., Impens I., A fractal-based Populus canopy structure model for the calculation of light interception, For. Ecol. Manage. 69 (1994) 97-110.

[14] Cluzeau C., Dupouey J.L., Courbaud B., Polyhedral representation of crown shape. A geometric tool for growth modelling, Ann. Sci. For. 52 (1995) 297-306.

[15] Coll L., Balandier P., Picon-Cochard C., Prevosto B., Curt T., Competition for water between beech seedlings and surrounding vegetation in different light and vegetation composition conditions, Ann. For. Sci. 60 (2003) 593-600.

[16] Comeau P.G., LITE : A model for estimating light under Broadleaf and Conifer tree canopies, report No. 23, Ministry of Forests Research Program British Columbia, 1998, 4 p.

[17] Comeau P.G., Measuring light in forest, report No. 42, Ministry of Forests Research Program, British Columbia, 2000, 7 p.

[18] Comeau P.G., Heineman J.L., Predicting understory light microclimate from stand parameters in young paper birch (Betula papyrifera Marsh.) stands, For. Ecol. Manage. 180 (2003) 303-315.

[19] Courbaud B., De Coligny F., Cordonnier T., Simulating radiation distribution in a heterogeneous Norway spruce forest on a slope, Agric. For. Meteorol. 116 (2003) 1-18.

[20] Dai X., Influence of light conditions in canopy gaps on forest regeneration : a new gap light index and its application in a boreal forest in east-central Sweden, For. Ecol. Manage. 84 (1996) 187-197.

[21] Dauzat J., Simulated plants and Radiative transfer simulations, in: Varlet-Grancher C., Bonhomme R., Sinoquet H. (Eds.), Crop structure and light microclimate: Characterization and applications, 1993, pp. 271-278.

[22] De Castro F., Fetcher N., Three dimensional model of the interception of light by a canopy, Agric. For. Meteorol. 90 (1998) 215-233.

[23] De Castro F., Light spectral composition in tropical forest: measurement and model, Tree Physiol. 20 (2000) 49-56.

[24] De Coligny F., Site Capsis 4, http://coligny.free.fr/.

[25] De Coligny F., Ancelin P., Cornu G., Courbaud B., Dreyfus P., Goreaud F., Gourlet-Fleury S., Meredieu C., Orazio C., SaintAndré L., Capsis: Computer-Aided Projection for Strategies In Silviculture: Open architecture for a shared forest-modelling platform, IUFRO Working Party S5.01-04 conference, September 2002, Harrison, British Columbia, Canada, 2002, pp. 371-380.

[26] Dhôte J.F., De Hercé E., Hyperbolic model for adjustment of sets of height diameter curves, Can. J. For. Res. 24 (1994) 1782-1790.

[27] Emborg J., Understorey light conditions and regeneration with respect to the structural dynamics of a near-natural temperate deciduous forest in Denmark, For. Ecol. Manage. 106 (1998) 83-95.

[28] Endler J.A., The color of light in forests and its implications, Ecol. Monogr. 63 (1993) 1-27.

[29] Frech A., Leuschner C., Hagemeier M., Holscher D., Neighbordependent canopy dimensions of ash, hornbeam, and lime in a species-rich mixed forest (Hainich National Park, Thuringia), Forstwiss. Centralbl. 122 (2003) 22-35.
[30] Gersonde R., Battles J.J., O'Hara K.L., Characterizing the light environment in Sierra Nevada mixed-conifer forests using a spatially explicit light model, Can. J. For. Res. 34 (2004) 1332-1342.

[31] Groot A., A model to estimate light interception by tree crowns, applied to black spruce, Can. J. For. Res. 34 (2004) 788-799.

[32] Grote R., Estimation of crown radii and crown projection area from stem size and tree position, Ann. For. Sci. 60 (2003) 393-402.

[33] Hale S.E., The effect of thinning intensity on the below-canopy light in a Sitka spruce plantation, For. Ecol. Manage. 179 (2003) 341-349.

[34] Hanan N.P., Enhanced two-layer radiative transfer scheme for a land surface model with a discontinuous upper canopy, Agric. For. Meteorol. 109 (2001) 265-281.

[35] Heindl M., Winkler H., Vertical lek placement of forest-dwelling manakin species (Aves, Pipridae) is associated with vertical gradients of ambient light, Biol. J. Linn. Soc. 80 (2003) 647-658.

[36] Kimes D.S., Smith J.A., Simulation of solar radiation absorption in vegetation canopies, Appl. Opt. 19 (1980) 2801-2811.

[37] Kimes D.S., Kirchner J.A., Radiative transfer model for heterogeneous 3-D scenes, Appl. Opt. 21 (1982) 4119-4129.

[38] Kimmins J.P., Forest ecology: a foundation for sustainable management, Macmillan Publ. Co., New York, 1997.

[39] Koop H., Forest Dynamics, SILVI-STAR: a comprehensive monitoring system, Springer-Verlag, Berlin, 1989.

[40] LeRoux X., Gauthier H., Begue A., Sinoquet H., Radiation absorption and use by humid savanna grassland: assessment using remote sensing and modelling, Agric. For. Meteorol. 85 (1997) 117-132.

[41] MacFarlane D.W., Green E.J., Brunner A., Burkhart H.E., Predicting survival and growth rates for individual loblolly pine trees from light capture estimates, Can. J. For. Res. 32 (2002) 19701983.

[42] MacFarlane D.W., Green E.J., Brunner A., Amateis R.L., Modeling loblolly pine canopy dynamics for a light capture model, For. Ecol. Manage. 173 (2003) 145-168.

[43] McMurtrie R., Wolf L., A model of competition between trees and grass for radiation, water and nutrients, Ann. Bot. 52 (1983) 449458.

[44] Meloni S., Sinoquet H., Assessment of the spatial distribution of light transmitted below young trees in an agroforestry system, Ann. Sci. For. 54 (1997) 313-333.

[45] Meloni S., A simplified description of the tree-dimensional structure of agroforestry trees for use with a Radiative transfer model, Agrofor. Syst. 43 (1999) 121-134.

[46] Messier C., Doucet R., Ruel J.C., Claveau Y., Kelly C., Lechowicz M.J., Functional ecology of advance regeneration in relation to light in boreal forests, Can. J. For. Res. 29 (1999) 812-823.

[47] Muth C.C., Bazzaz F.A., Tree canopy displacement at forest gap edges, Can. J. For. Res. 32 (2002) 247-254.

[48] Muth C.C., Bazzaz F.A., Tree canopy displacement and neighborhood interactions, Can. J. For. Res. 33 (2003) 1323-1330.

[49] Nigh G.D., Love B.A., Predicting crown class in three western conifer species, Can. J. For. Res. 34 (2004) 592-599.

[50] Oker-Blom P., Kaufmann M.R., Ryan M.G., Performance of a canopy light interception model for conifer shoots, trees and stands, Tree Physiol. 9 (1991) 227-243.

[51] Parker G.G., Davis M.M., Moon Chapotin S., Canopy light transmittance in Douglas-fir-western hemlock stands, Tree Physiol. 22 (2002) 147-157. 
[52] Piboule A., Influence de la structure du peuplement forestier sur la distribution de l'éclairement sous couvert. Cas d'une forêt hétérogène feuillue sur plateau calcaire, Thèse de Doctorat, École Nationale du Génie Rural, des Eaux et des Forêts, Nancy, 2005.

[53] Pritchard J.M., Comeau P.G., Effects of opening size and stand characteristics on light transmittance and temperature under young trembling aspen stands, For. Ecol. Manage. 200 (2004) 119-128.

[54] Ricard J.P., Messier C., Delagrange S., Beaudet M., Do understory sapling respond to both light and below-ground competition? A field experiment in a north-eastern American hardwood forest and a literature review, Ann. For. Sci. 60 (2003) 749-756.

[55] Riegel G.M., Miller R.F., Krueger W.C., The effects of aboveground and belowground competition on understory species composition in a Pinus ponderosa forest, For. Sci. 41 (1995) 864-889.

[56] SAS Institute Inc., SAS System for Windows Version 8, 2000, Cary, NC: SAS Institute Inc.

[57] Song B., Chen J.Q., Desanker P.V., Reed D.D., Bradshaw G.A., Franklin J.F., Modeling canopy structure and heterogeneity across scales: From crowns to canopy, For. Ecol. Manage. 96 (1997) 217229.

[58] Sonohat G., Balandier P., Ruchaud F., Predicting solar radiation transmittance in the understory of even-aged coniferous stands in temperate forests, Ann. For. Sci. 61 (2004) 629-641.
[59] Stadt K.J., Lieffers V.J., MIXLIGHT: a flexible light transmission model for mixed-species forest stands, Agric. For. Meteorol. 102 (2000) 235-252.

[60] Ter-Mikaelian M.T., Wagner R.G., Shropshire C., Bell F.W., Swanton C.J., Using a mechanistic model to evaluate sampling designs for light transmission through forest plant canopies, Can. J. For. Res. 27 (1997) 117-126.

[61] Toutain F., Les humus forestiers : structure et mode de fonctionnement, Rev. For. Fr. 32 (1981) 449-479.

[62] Vera F.W.M., Establishment of trees and shrubs in relation to light and grazing, in: Vera F.W.M. (Ed.), Grazing ecology and forest history, Chapter 6, CABI Publishing, New York, 2000, pp. 287-368.

[63] Wang H., Baldocchi D.D., A numerical model for simulating the radiation regime within a deciduous forest canopy, Agric. For. Meteorol. 46 (1989) 313-337.

[64] West P.W., Wells K.F., Method of application of a model to predict the light environment of individual tree crowns and its use in a eucalyptus forest, Ecol. Model. 60 (1992) 199-231.

[65] Wetzel S., Burgess D., Understorey environment and vegetation response after partial cutting and site preparation in Pinus strobus L. stands, For. Ecol. Manage. 151 (2001) 43-59. 